\title{
Municipal Waste Management: the Calabrian Case
}

\author{
Francesco Saverio Nesci ${ }^{1, a}$, Donatella Privitera ${ }^{2, b}$ \\ ${ }^{1}$ Mediterranea University of Reggio Calabria - Department of Agricultural Sciences \\ Località Feo di Vito - 89124 - Reggio Calabria - Italy \\ ${ }^{2}$ University of Catania - Science Department of Education \\ Via Biblioteca 4 - Palazzo Ingrassia - 95124 Catania - Italy \\ afrancesco.nesci@unirc.it \\ bdonatella.privitera@unict.it
}

Keywords: Municipal Solid Waste, Urban Attractiveness, Local Development.

\begin{abstract}
This paper tackles the issue of municipal waste collection and disposal in the light of the environmental and health demands and emergencies coming from urban areas. Starting from an overview of the European situation, the case of the Calabrian region will be analysed, in order to hypothesise effective management interventions and disposal systems.
\end{abstract}

\section{Introduction}

In Italy, municipal waste management, at the expense of public bodies, has recently reported a growing interest in terms of technology and organisation. Considering waste as a resource is not only beneficial from an economical point of view, but also in the perspective of an environmentfriendly development, according to a model that has already been introduced in many industrialised Countries [1].

Waste represents an urgent environmental, social and economic problem, and the latest EU guidelines and juridical instruments set its management as a priority; the Waste Framework Directive (2008/98/CE) determines that waste related issues must be considered independently from economic growth and garbage effects on the environment and it represents the general framework for waste management; in this framework, a good organization of the whole process is reported to be the first and most important element.

The same Directive determines that prevention, preparing for re-use, recycling and other recovery and disposal must all be intended for a "recycling society", in order to reduce waste production and to use produced waste as a resource. It supports the polluter-pays principle (a guiding principle at European and international levels) according to which the waste producer and the waste holder should manage the waste in a way that guarantees a high level of protection of the environment and human health.

Italian legislation on waste management refers to art. 183 of D.L. 152/2006, then modified by D.L. 205/2010, "Dispositions for the implementation of the Waste Framework Directive 2008/98/CE issued by the European Parliament and Council on $19^{\text {th }}$ November 2008 abrogating other directives" (GU n. 288 of 10-12-2010 - Ordinary Suppl. n. 269): it states that waste is " any substance or object which a holder disposes or which he wants or needs to dispose».

The field of economics of waste includes studies that date back before the 1980s [2] and which increasingly emphasize policy aspects [3]. Due to data availability, applied analysis has lagged behind theoretical analysis until recently [4].

Aim of this work is to highlight critical factors connected to the issue of municipal solid waste, and in particular their occurrence in the Calabrian Region, by analysing the current situation.

\section{Overview of the European situation}

According to Eurostat data, urban waste production in EU27 reported a downward trend of 0,9\% compared to 2010. In particular, data related to waste management in 2011, according to what is 
shown in [5], report that about $36 \%$ was disposed in garbage dumps, $23 \%$ was destined to incineration, while $26 \%$ and $15 \%$ were respectively intended for recycling and compost making (the latter including all biodegradable fractions of waste that were anaerobically processed). If we take into account all the different ways in which different Countries manage waste, we can easily detect unethical Countries, as those belonging to southern and eastern areas, featured by few stations (waste to energy plants, compost making stations, sludge treatment), low percentages of separate collection and a consequent high inflow to garbage dumps; on the contrary, in ethical Countries, as central and northern areas, thanks to a wide variety of working stations and to policies incentivizing waste reduction and recycling, garbage dump usage has been strongly reduced, if not eliminated throughout.

In particular [fig.1], new EU 27 member states make great use of land filled (average 240 $\mathrm{kg} /$ inhabitant/year), more that 90\% (92\% Malta, 94\% Bulgaria and 99\% Romania) while, among EU15 Countries, where the average amount of waste intended for landfilled is 159 $\mathrm{kg} /$ inhabitant/year, percentages are much lower (below 1\% in Germany, the Nederland and Sweden, and below 5\% in Denmark, Belgium and Austria).

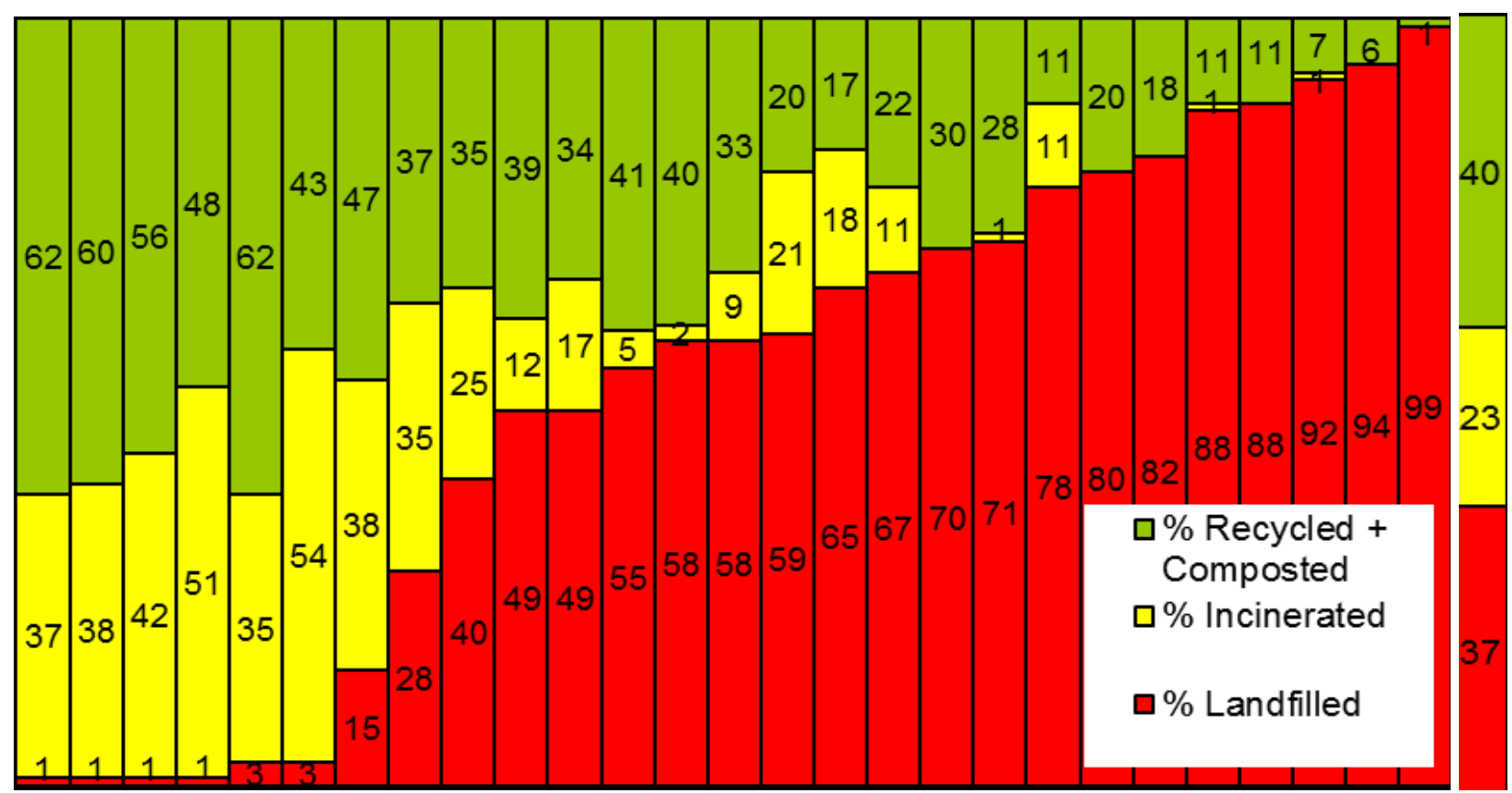

Fig. 1 - Municipal waste management in EU 27 (\%) - [5] according to Eurostat data in 2011 DE NL BE SE AT DK LU FR FI UK IT IE SL ES PT CZ HU EE PL SK CY GR LT LV MT BG RO EU27*

*Germany, Nederland, Belgium, Sweden, Austria, Denmark, Luxembourg, France, Finland, United Kingdom, Italy, Ireland, Slovenia, Spain, Portugal, Czech Republic, Hungary, Estonia, Poland, Slovakia, Lithuania, Cyprus, Greece, Latvia, Malta, Bulgaria, Romania.

This result is as expected based on the fact that Austria and Germany are leaders in the waste sector and in waste management and show performances above the EU average [6].

European commission guidelines show that a good mix of taxes and bans on land filled and incineration, together with awareness campaigns intended for waste producers and pay as you throw systems result in being the most effective solution to address waste towards more sustainable directions. Several studies [7] proved the effectiveness of these principles. Waste inflows to land filled and incineration have reduced in those Countries where the cost had increased due to taxes and bans. Moreover, these solutions proved to be efficient in preventing waste production and encourage citizens to support separate collection. At the same time, awareness raised among producers let several member States collect and distribute the necessary funding to improve separate collection and recycling. 


\section{Italy and municipal waste management}

In Italy, municipal waste inflow to garbage dump is $49 \%$ against an average $37 \%$ of EU27; separate collection values amount to $35.3 \%$, with a remarkable difference among its regions [5]. The worst regions are Sicily (83\% and $404 \mathrm{~kg} /$ inhabitant), Calabria (81\% and $356 \mathrm{~kg} /$ inhabitant) and Liguria (66\% and $388 \mathrm{~kg} /$ inhabitant). The national record for underground waste disposal is achieved by Lazio (2,1 million t.), followed by Sicily and Puglia, without making any reference to the issue of unlawful disposal.

According to the Ispra report 39\% of municipal waste was buried. In Italy in 2012, equal to 11,7 million t., which is $196 \mathrm{~kg} / \mathrm{inhabitant} / \mathrm{year}$, in more than 400 authorized garbage dumps, half of which are still working. However, in the last 20 years, European regulations have arranged that land filled usage must be confined to residual waste that must not be overburdened nor intended for recycling.

The European Commission demanded that Italy recovers abandoned stations and start infringement procedures, referred to the Court of Justice, for the reclamation of the several unlawful garbage dumps on its territory.

According to data released by the Ministry for environment, about 15 million t. of waste, almost half of their total amount, flowed into authorized garbage dumps. 186 is the number of working garbage dumps in 2012, 79 of them was in the North, 66 in the Centre and 41 in the South. The region with the highest number of stations is Emilia Romagna (18), followed by Piedmont (16), Sicily, Tuscany e Trentino Alto Adige (14). In 2012, separate collection at national level was 39.9\% (37.7\% in 2011) but there is a strong difference between the north, where the percentage for separate collection is higher than $50 \%$, and the south and centre where percentages are $32.9 \%$ and 26.7\%. At regional level, in Veneto and Trentino Alto Adige $62.6 \%$ and $62.3 \%$ of waste is respectively destined to separate collection, while Sicily and Calabria report the lower rate of $15 \%$ $[5]$.

The main problem is that waste disposal in garbage dumps is in many regions cheaper than other solutions: in Puglia, for instance, the average cost is $50 € / \mathrm{t}$. while in Lazio the average cost ranges from 40 to $70 € / t$. Where costs are higher, separate collection and recycling are more convenient, as showed by more advanced regions as Veneto, where waste disposal in garbage dumps can cost up to $150 € / \mathrm{t}$, or Trentino, where it costs $119 € / \mathrm{t}$.

In order to economically disadvantage waste burying and discourage this process, the Parliament used to apply a regional Eco tax on waste disposal in garbage dumps (L. 549/95). It was rarely enforced in full but, when applied, it had remarkable results. This is the case of Sardinia and, especially, Marche where the eco-tax was enforced to award the most ethical municipalities.

One of the reasons for this backward condition is the lack of processing and disposal plants, like waste to energy plants, that could produce remarkable partially renewable quantities of heat and electric energy out of waste. Only 46 plants are present in Italy serving over 60 million inhabitants, while in France 129 plants serve 65 million inhabitants, in Denmark 29 plants serve 7 million inhabitants and in Germany 75 plants can process an amount of waste that is four times higher than the one processed in Italy [8].

\section{Case Study: the city of Reggio Calabria}

Calabria covers a surface of $15,000 \mathrm{~km}^{2}$, divided into 5 provinces, with over 2,000,000 inhabitants in 409 Municipalities, and 800 urban centres, with a density of 133 inhabitants $/ \mathrm{km}^{2}$. Concerning the relationship between population density, territory and a number of urban centres, less than $25 \%$ of the population live in municipalities with more than 25,000 inhabitants and about $50 \%$ in municipalities with less than 10,000 inhabitants; in particular, about 280,000 inhabitants, $14 \%$ of the regional population live in 225 municipalities with a population of between 400 and 2,500 inhabitants.

At the end of 1990s. the Region fell into a never ending condition of environmental emergency, with an expense of more than 1,000 million $€$ (Parliamentary Fact Finding Committee on unlawful activities related to waste management in Calabria). 
Data per province (as released by the Office of the commissioner for waste emergency, 2007) show that the total production of waste amounts to 1 million t., $82 \%$ of this is municipal solid waste, with a per capita average of $493 \mathrm{~kg}$, starting from a minimum of $466 \mathrm{~kg}$ in the province of Cosenza and a maximum of $533 \mathrm{~kg}$ in the province of Crotone.

The implemented policies have not allowed an appropriate planning of waste management in terms of sustainability, as they were only intended to enlarge existing dumps, planning new ones and double the number of incineration plants, aiming at enhancing energy as expected by the EU.

The plan currently operating in Calabria (2007) is based on a division of the territory in three macro areas: North, Centre and South; each of them is divided in 5 territorial frameworks (ATO), that correspond to provincial territories, each of which is divided in sub-frameworks managed by ad hoc Commissioners.

Within ATOs, with their poor homogeneity and serious viability problems, there are 7 plants for mechanic and biologic processing, 8 plants for compost making out of selected organic fractions, 11 land filled and 1 incineration plant. Plan Guidelines on waste disposal in garbage dumps and/or incineration plants set the following commitments with reference to pre-processing of mixed waste: the necessity to operate mechanic/biologic pre-processing before waste disposal in garbage dumps or energetic enhancement; the qualification of dry parts from processed waste; appropriate valorisation of existing plants on the regional territory; implementation of new plants on the territory in order to fulfil the request for mixed waste pre-processing; concerning new plants, refer to selection/stabilization processes and anaerobic digestion in order to facilitate the processing of wet waste separately collected; achieve remarkable results in energetic terms.

With a decreasing trend in the last 5 years due to the general crisis, Calabria produces 865,000 t./year including separate collection; $29 \%$ is produced in the province of Reggio Calabria, $20 \%$ in the province of Catanzaro, $34 \%$ in the province of Cosenza, $9 \%$ in the province of Crotone and $8 \%$ in the province of Vibo Valentia. 34\% of this production is disposed in garbage dumps as, municipal solid waste; $4-5 \%$ is collected separately and destined to recycling (definitely below the declared rate of $12 \%$ [5]) and the remaining part, between $54-66 \%$, is destined to mechanic-biologic processing plants for the separation of dry and wet waste and intended for the production of fuel out of municipal waste $(35 \%) ; 40 \%$ of organic stabilized fraction; $20-28 \%$ garbage (dry parts that cannot be used) and 5\% of iron (intended for recycling) and process waste.

Based on released data [5], Calabria is the last region in the ranking for separate collection per capita/year, with about $60 \mathrm{~kg}$ (2012), remarkably below the values reported for northern Italy ranging between 250 and $340 \mathrm{~kg}$.

The Parliament Fact Finding Committee highlights that mechanic-biologic processing plants are not appropriately distributed on the territory and are featured by an exceeding production of refuses, equal to $40 \%$ of incoming solid waste, against the national average of $23-24 \%$; moreover it shows that the region is lacking in that typology of plants that, according to the current state of technology and its consequent apply to industry, guarantee a more efficient disposal of waste. Calabrian stations simply "sieve" waste, sending them to the garbage dump/incinerating plant, starting up a vicious circle that is both dangerous for the environment and expensive.

The Commission Report states that: " ..such and evident underuse, and consequent waste, of existing plants built thanks to public funding is due to an almost total lack of separate collection; as a consequence, the organic selection within the separate collection is not sufficient to be appropriately processed in the mentioned plants".

Sanitary landfills are 6 in the province of Cosenza, 2 in the province of Catanzaro, 2 in the province of Reggio Calabria, 1 in the province of Crotone and they are absent in the province of Vibo Valentia. The only incinerating plant is in Gioia Tauro (2008), with a potential of 120,000 $\mathrm{t} /$ year of fuel deriving from municipal waste; only $80 \%$ of it is used and just $10 \%$ is produced in Calabria.

The waste to energy plant of Gioia Tauro is perfectly sufficient (despite duplication having been suggested) in terms of quantity; however its management is utterly inappropriate as the fuel 
produced is not compatible with the same plant and thus causes continuing faults with resulting interruptions on service.

Calabria is featured by an excessive scarcity of separate collection, but the real problem affecting the 409 municipalities is represented by unlawful garbage dumps; in fact, 696 sites are polluted due to an amount of waste higher than $250 \mathrm{mc}$.; 240 of these sites are only used for municipal solid waste, 4 of which for special dangerous waste; 5 for big size waste; 4 for aggregates and construction materials while the rest is represented by sites for generic waste.

Working plants for the selection and production of fuel out of waste are three and they are located in Siderno, Reggio Calabria and Gioia Tauro, where the waste to energy plants works to burn the production coming from the other two plants that are subsequently disposed to the garbage dump of Rossano (CS). The landfill of Casignana serves 24 municipalities on the southern part of the Ionian coast; however its activity is highly questioned due to the project for its enlargement on an area that had already been dismissed for being overfilled.

\section{Conclusions}

In line with community guidelines, Italy should oppose landfill disposal, eliminating any incentive to energy recovery out of waste; on the contrary it should support recycling making it more convenient and promoting prevention policies according to the polluter pays principle. A new incentivizing system should be set together with policies aimed at discouraging waste integrated cycle. Eliminating waste combustion is as important as discouraging the establishment of new incinerating plants, except from plants intended for biogas production out of separate organic waste.

In Calabria the plan drafted by the Department for environmental policies of the Calabria Region is already working and it is dealing with the regeneration of high risk polluted areas. However, the issue of the unlawful landfills is extremely serious as these are located not only nearby rivers or hidden areas but also close to urban centres, endangering public health together with the tourist image that the territory could offer.

In order to get out of the perennial condition of emergency that the region is undergoing, we need to implement a system able to solve the problem of waste management following the model of other European Countries and Italian regions. The local community needs to be involved in order for it to take responsibility of the decisions made, even in terms of management. The system must be based on communication and re-education, reduction of waste production, reuse of refuse, separate collection and recycling. Increased delinking is the primary aim for waste, which, in terms of its environmental impacts and economic costs, is no less relevant than climate change and it is also a cause of the greenhouse gas emissions generated by various disposal options [1]. It seems necessary to implement a compost making plant, preferably in rural areas thus more useful for farmers, and stations for recycling and material recovery, aimed at products redirection onto the production chain. Intervention for the reduction of waste amount are equally important; they could use recyclable materials and, where possible, reuse and repair materials to be sent to specialized centres, which would increase satellite activities. It is necessary to define tariffs that reward responsible citizens encouraging them to be aware of what they purchase and to produce less unrecyclable waste. Research can allow the industrial re-planning of non-recyclable items; moreover it can provide companies with feedback and promote the best practices for purchasing, production and consumption. 


\section{References}

[1] R. Cossu, S. Masi: Re-thinking incentives and penalties: Economic aspects of waste management in Italy, in Waste Management vol. 33 (2013), pp. 2541-2547.

[2] C. Choe, I. Fraser: An economic analysis of household waste management, in Journal of Environmental Economics and Management 38 (1999), pp. 234-46.

[3] M. Walls, K. Palmer: Upstream pollution, downstream waste disposal and the design of comprehensive environmental policy, in Journal of Environmental Economics and Management, 41 (2001), pp. 94-108.

[4] N. Johnstone, J. Labonne: Generation of household solid waste in OECD countries. An empirical analysis using macroeconomic data, in Land Economics vol. 80 (4) (2004), pp. 529-38.

[5] Ispra: Rapporto rifiuti urbani, Roma (2013).

[6] V. Iafolla, M. Mazzanti, F. Nicolli: Are You SURE You Want to Waste Policy Chances? Waste Generation, Landfill Diversion and Environmental Policy Effectiveness, in the EU15, working paper, Fondazione Enrico Mattei (2010).

[7] F. Andersen, H. Larsen, M. Skovgaard: Municipal waste generation, management and greenhouse gas emissions, in: Waste and Environmental Policy, edited by M. Mazzanti, A. Montini, Routledge, London (2009).

[8] CEWEP, Maps of European Waste to Energy Plants, (2011), information on http://www.cewep.eu/ 